\title{
What is a Beautiful Experiment?
}

\author{
Milena Ivanova $^{1} \mathbb{D}$
}

Received: 13 August 2021 / Accepted: 21 December 2022

(c) The Author(s) 2022

\begin{abstract}
This article starts an engagement on the aesthetics of experiments and offers an account for analysing how aesthetics features in the design, evaluation and reception of experiments. I identify two dimensions of aesthetic evaluation of experiments: design and significance. When it comes to design, a number of qualities, such as simplicity, economy and aptness, are analysed and illustrated with the famous Meselson-Stahl experiment. Beautiful experiments are also regarded to make significant discoveries, but I argue against a narrow construal of experimental aims. By drawing on the plurality of goals experimenters have and diversity of aesthetic responses, I argue that experiments are aesthetically appreciated both when they discover and when they produce disruptive results.
\end{abstract}

\section{Introduction}

Much philosophical attention has recently been given to the relationship between aesthetics and science. In addition to a number of collections exploring connections between philosophy of science and philosophy of art (Bueno et. al 2017; Frigg and Hunter 2010) and fiction and imagination in science (Godrey-Smith and Levy 2020), recently an entire volume was dedicated exploring the role of aesthetic evaluations in science (Ivanova \& French, 2020). The latter offers a number of new directions on how beauty affects the evaluation of scientific theories and can guide theory choice in cases of underdetermination, the relationship between beauty on one hand, and truth and/or the acquisition of understanding on the other, and experiences of the sublime in science. The primary focus of these works has been scientific theories and their aesthetic value. However, there is also a very productive engagement emerging that focuses on scientific practices beyond the theory, and exploring their aesthetic dimensions. For instance, Wiley (2015, 2021), Turner (2019) and Currie (2020) offer illuminating studies of aesthetic factors operating in the preparation of fossils in palaeontology, Parsons (2012) explores how aesthetic factors affects the

Milena Ivanova

mail@milenaivanova.co.uk

1 Fitzwilliam College, University of Cambridge, Storey Way, Cambridge CB3 ODG, UK 
study of proteins in chemical biology, Ambrosio and Clarke (2018) study aesthetics in anatomy, while Elgin (2014) and Murphy (2020) discuss the aesthetic nature of thought experiments by drawing analogies to literary works. While the philosophical engagement on the relationship between science and aesthetics is blooming, there seems to be a significant gap in the current literature when it comes to another important aspect of scientific activity: the experiment. Such an absence of philosophical attention to the aesthetic nature of experimentation seems hard to justify since, like theories, experiments are regarded as having aesthetic properties, as being beautiful, and to generate aesthetic responses. Experiments also play a crucial role in the exploration of phenomena and target systems, establishing the tenability of theories, discovering new phenomena, entities, techniques and experimental methods. Given their significance, it is crucial to ask whether aesthetic factors play any interesting roles in scientific experimentation. This article aims to fill this gap by offering a new framework for analysing the aesthetic significance of experiments and identifying a number of important questions for the further advancement of this literature. I show how aesthetic judgements feature in the design, appraisal and reception of an experiment and defend the cognitive value of aesthetic judgements in experimentation.

I start Sect. 2 with an overview of the current literature on the aesthetics of science, outlining a number of questions that have received systematic attention, such as whether we should take the aesthetic discourse that occurs in science seriously, what constitutes beauty in science, whether aesthetic values are stable or changing, and whether they can play any epistemic roles in science. After drawing this literature map, in Sect. 3 I turn to defining what constitutes a beautiful experiment, identifying a number of contenders concerned with the design of the experiment, such as its elegance, simplicity, economy and aptness: how well it was designed to serve its purpose. I illustrate this account with a case study from molecular biology, the famous Meselson-Stahl experiment, often referred to as 'the most beautiful experiment in biology'. Having analysed the design aspect of aesthetic appreciation of experiments, in Sect. 4 I focus on the aesthetic appreciation of their results. I argue that when addressing the question of whether an experiment is beautiful, we need to draw a distinction between design and significance, both of which have been the subject of aesthetic praise by scientists. I defend a pluralistic approach to experimentation and aesthetic value, arguing that experiments are aesthetically valuable both when they confirm or discover and when they produce probing results. I conclude that both the design of an experiment and its results should be considered when analysing the aesthetic value of an experiment and that aesthetic appreciation plays an important cognitive role in science.

\section{Aesthetics and Science: The State of the Art}

Aesthetics features prominently in scientific engagement. We can identify several levels at which aesthetic considerations and judgements enter in scientific activities. The subject of our investigations, nature itself, affords us aesthetic experiences. Scientists often claim that nature is beautiful and refer to specific phenomena, such 
as microscopic cell structures, rainbows, honeycombs, stalagmites, as beautiful, as generating in us feelings of awe and wonder. ${ }^{1}$ Products of scientific activities are also aesthetically appraised. Pictures of oscillating particles, scientific models like the structure of DNA molecules, mathematical proofs like Euclid's Elements, experiments like Rutherford's explorations of uranium radiation, and many scientific theories, from Newton's and Einstein's theories of gravity, to the standard model and evolutionary theory, are claimed to be aesthetically valuable and beautiful. Furthermore, the process by which scientists arrive at a product, whether constructing a proof or an experiment or arriving at a theory, is considered analogous to an artistic production subject to aesthetic judgement. Scientists, like artists, are praised for their creative and imaginative thinking and use of their aesthetic sensibility, with the French physicist Pierre Duhem arguing that:

[I]t is impossible to follow the march of one of the great theories of physics, to see it unroll majestically its regular deductions starting from initial hypotheses, to see its consequences represent a multitude of experimental laws down to the small detail, without being charmed by the beauty of such a construction, without feeling keenly that such a creation of the human mind is truly a work of art (Duhem, 1954, p. 24).

Ernest Rutherford similarly reflects that theories can be seen as artistic productions: "a strong claim can be made that the process of scientific discovery may be regarded as a form of art. [...] A well constructed theory is in some respects undoubtedly an artistic production." (quoted in McAllister, 1996, p. 14).

It is clear that aesthetic judgements feature in all these levels of scientific practice but what role do they play? During the logical positivist tradition, aesthetic considerations were deemed only relevant in the context of discovery. Since they were regarded as subjective, aesthetic considerations were given no bearing in the context of justification, which involves the formal relationship between the theory and the evidence. More recent studies on the nature of observation, evidence and practice more generally have challenged the demarcation between these two phases of scientific development, with arguments defending the involvement of aesthetic judgements in the construction and evaluation of evidence as well (Cellucci, 2015; French, 2020a, b; Ivanova \& French, 2020; Wiley 2021). An alternative line of scepticism has been expressed by Todd (2008), who challenges the idea that the aesthetic judgements we see in science are indeed of aesthetic nature, given the difficulty in defining the nature of the aesthetic response, and claiming that aesthetic judgements are ultimately concealed epistemic judgements. However, two lines of arguments have been offered to motivate taking scientist's aesthetic judgements seriously. First, against the idea that beauty claims about scientific products are reducible to claims about their empirical success, we run into the problem that often theories, for instance, are judged to be beautiful when they lack evidential support. Such is the case in modern physics, where it is becoming progressively hard to test theories in

\footnotetext{
1 Different accounts have been proposed regarding the aesthetic appreciation of nature. For a detailed discussion see Carlson (2011), Parsons (2002) and Turner (2019).
} 
high-energy domains, and physicists appeal more and more to aesthetic arguments to support their beliefs in the theory (Ivanova 2020). Furthermore, as we will see in more detail below, we also often attribute aesthetic value to theories that are not epistemically successful. For instance we appreciate the beauty of the Kaluza-Klein theory even if it is not an empirically successful theory. Second, there seems to be some empirical evidence from neuroscience suggesting that the cognitive processes unfolding during the aesthetic appreciation of artworks is the same as that involving appreciation of scientific products, giving us at least some motivation to explore the common nature of aesthetic appreciation of artworks and scientific products (Ivanova, 2017a).

Those that have taken scientists' aesthetic judgements literally have been occupied with two central questions: (1) what is the nature of aesthetic judgements in science: are they stable or changing?; and (2) what kind of role do these judgements play in science, are they motivational or cognitive? Starting with the latter question, it has been argued that aesthetic judgements in science are of purely motivational nature, with the famous mathematician Henri Poincaré claiming that "[t]he scientist does not study nature because it is useful to do so. He studies it because he takes pleasure in it, and he takes pleasure in it because it is beautiful" (2001, p. 368). Beyond its motivational role, some give beauty a much more substantial role in their reasoning, arguing that aesthetically valuable theories are more likely to be true. Take, for instance, Paul Dirac's claim that the beauty of general relativity was what motivated his trust in the theory before it was empirically supported: "one has a great confidence in the theory arising from its great beauty, quite independently of its detailed successes" (Dirac 1980, 40). Dirac's sentiments are certainly not unusual. A number of scientists have defended such a link, with the Nobel Laureate Chandrasekhar, offering a series of arguments in his book Beauty and Truth, showing the historical relationship between beautiful theories and their truthlikeness.

How has such a link between truth and beauty been justified? A long-standing tradition, going back to Robert Boyle and Isaac Newton, has it that nature is beautiful, simple, well-ordered, so the beauty of our theories simply reflects the beauty of nature. More recently, empirical arguments have been advanced that take the track record of theories with aesthetic properties and infer that these properties can justify our trust in contemporary theories. Scientific realists, for instance, have argued that virtues such as simplicity, unity and economy can be used to evaluate the plausibility of a theory when the evidence is not yet available to support it. Richard Boyd (1984) argues that theories possessing theoretical virtues that have been instantiated by previously successful theories will be ranked as more plausible while Wesley Salmon (1990) goes further in showing how these virtues can bear upon the confirmation of a theory by showing that the past record of success will ultimately determine the prior probability of a theory. Such track record argument, involving the aesthetic values of theories, is also developed by James McAllister (1996), although the focus of his work is not to defend scientific realism and the relationship between beauty and truth, but to argue for the rational employment of aesthetic factors in the evaluation and adoption of a theory. The underlying idea is that we can extract which aesthetic qualities have been associated with historically successful theories and rationally employ new theories that possess these qualities too. 
There is, however, also scepticism with regard to such track record arguments. Sabine Hossenfelder (2018) discusses a number of illuminating examples from theoretical physics in which theories of great aesthetic merit are abandoned due to their lack of predictive success, such as steady state universe, Platonic solids, KaluzaKlein theory. Hossenfelder argues that we should proceed with care when it comes to beauty guiding our belief in theories, because beauty can often be a systematic bias that leads away from developing successful theories. And when it comes to placing confidence in the track record of 'ugly' theories, our current best theories in physics - the standard model and quantum mechanics-provide examples of great empirical and predictive success but are rarely used as examples of beautiful theories, quite the contrary. In a similar manner, in Ivanova (2020) I argue that track record arguments are inconclusive, since both 'optimistic' and 'pessimistic' arguments can be supported from the history of science.

More recently, we have seen a shift in the debate on the aim of science, with some now focusing on understanding rather than truth as the primary goal of science. This shift of philosophical attention has been motivated by the observation that science often achieves understanding by utilising highly abstracted and idealised models that depart from what our best scientific theories tell is to be true about the world (Potochnik, 2017; Elgin, 2018). In this context, beauty has been seen to play a regulative role with Breitenbach (2013), Elgin (2020), and Ivanova (2017a, 2017b, 2020) arguing that aesthetic values shape and guide our investigations and epistemic goals.

A further question that has occupied philosophers concerns the concept of beauty itself. If we were to place epistemic import on such a concept, shouldn't it be objective and rigid? The debate here concerns whether beauty can in any sense be seen to be an objective or stable concept, with many arguing that our aesthetic judgements differ among individuals, schools of thought and time periods. McAllister, for instance, argues that theory change can be understood as revolutions at the level of aesthetic values, arguing that beauty in science, very much like in art, is a dynamic and ever changing concept, with new aesthetic values taking over past ones. Despite such instability of aesthetic judgements in the history of science, McAllister ties beauty to utility and argues that it is rational to rely on aesthetic values despite their dynamicism, because aesthetic values are ultimately grounded in empirical success. However, not everyone is convinced about the revolutions of our aesthetic values in science, with some philosophers claiming that there is continuity when it comes to the core values employed in science. Peter Kivy (1991), for instance, observes that scientists consistently praise classic features and Ullian Montano (2012) further argues that some aesthetic values, such as simplicity and elegance, are 'historical constants', not losing centrality in scientific practice. This resistance to revise aesthetic canons and the stability of values such as economy, elegance, simplicity and symmetry, has been explained as reflecting facts about humans' cognitive capacities and other practical constraints, that make these values central to scientific practice (Ivanova 2020).

What we see in this fruitful engagement so far is an emphasis on scientific theorising, and the epistemic goods aesthetic values might be related to. But scientific engagement is a lot richer and it is important to explore at what other levels we can find aesthetic considerations operating in the practices of science. I thus hope that 
by exploring the aesthetic dimensions of experimental practice, we can shed some further light onto how we can address the above questions, especially when it comes to identifying whether we see different aesthetic appraisal during different experimental traditions, and how aesthetic values shape the design and reception of experiments. My aim in the next section is to focus on the concept of beauty in scientific experiments and ask (1) what constitutes a beautiful experiment?, and (2) how aesthetic considerations shape the experiment?.

\section{Beauty in Design: On the Simplicity, Economy and Elegance of Experiments}

Experiments have been praised for their aesthetic qualities from the early days of the Royal Society, where natural philosophers would perform experiments in front of audiences and would often report the experience of delight, awe and beauty. Joseph Priestley, for one, notes in his studies on electric phenomena that experiments on electric currents are "one of the most beautiful experiments" generating "the most delightful spectacle" (1775, 298). The focus of aesthetic appreciation during this time often concerns the unveiling of a beautiful natural phenomenon via the experiment. Although the instruments and materials used in the experiment, as well as the steps implemented of the experiment, were also acknowledged as beautiful, skilful and showing originality and creativity of the experimenter, the experiment was seen as a way to display nature's beauty. What receives particular attention at this time is the observed phenomenon, the beauty of the electric effect, giving rise to the experience of pleasure, awe, amusement (ibid., 504-506). ${ }^{2}$ Alexander WraggeMorley's recent (2020) study of the aesthetic considerations driving the members of the Royal Society in this period is instructive. He documents the aesthetic considerations at the forefront of natural philosophers, from the preparation of specimens, the design of experiments, the formulation of hypothesis and emphasises that these practices were deeply impacted by the belief that nature itself is beautiful, which in itself was grounded in the belief of a divine creator. For instance, Hooke's Micrographia (1665) illustrates the idea that simply reproducing the data of experience (the specimens) was considered unsatisfactory, that one had to provoke a feeling of pleasure and beauty when looking at the scientific object, thus producing a beautiful image. Examples of the artistic presentation of the object of scientific investigations are illustrated in the work of Hooke's depiction of the flea as seen under the microscope, and Leonardo Da Vinci's presentation of the human body in his sketches, to name a few.

\footnotetext{
${ }^{2}$ Defining an experience as aesthetic in nature and delineating it clearly from other experiences has been a difficult task. Noël Carroll (2002) distinguishes between axiological, content and affect oriented approaches. On the axiological approach, an aesthetic experience is worth having, independently on any instrumental value. The content approach seeks to identify common qualities in the object generating the experience, while the affect approach focuses on the qualities of the experience itself (see Beardsley (1982) for an affect oriented definition). For the purposes of this article, I will grant that there is an aesthetic experience without committing to a particular definition.
} 
Parsons and Reuger (2000) have argued that methodological shifts during the eighteenth century correlate with a shift in the aesthetic appreciation of experiments. While earlier experiments aim to study nature and were repeatedly performed following the inductive method, shifting to the hypothetico-deductive method directs towards experiments serving the purpose of testing the correctness of theories. As Parsons and Reuger argue:

$[\mathrm{N}]$ ow it is only with the assistance of the confirmed or illustrated theory that an experiment is thought to give us insight into nature. Whatever beauty is displayed in an experiment, it cannot be the beauty of nature itself; the economy of an experiment reflects the economy of our own cognitive households, not the economy of nature. This is clearly different from the view of the eighteen century natural philosopher who appreciates nature itself through the frame of the experiment. (ibid., 411)

Parsons and Reuger appeal to Allen Carlson's (1993) distinction between orderoriented and design-oriented appreciation, a distinction they take to reflect the two modes of appreciations we see in the early 17-eighteenth century and the later 18-nineteenth century traditions. What comes to be aesthetically appreciated in the later tradition is not nature's beauty itself, but the display of "“aptness' in the relation of result and tools, of plan and success" (ibid., 411). The experiment is now beautiful because it is "optimally suited to achieve its purpose" (ibid., 411-412). So what kinds of qualities receive attention in the experiments after this shift?

Aesthetic appraisal of experiments seems to focus on the simplicity, elegance, and aptness of the experiments. For instance, in his reflections on Ernst Rutherford's experiments on the artificial disintegration of atomic nuclei, Pyoter Kapitsa focuses on the simplicity of the experiments. He claims that these experiments are "exceptionally simple" $(1937,90)$ and that "any researcher, and not a physicist alone, cannot help but be astonished by this simplicity of the posing of the question, by the most simple experiment. Such simplicity can come only from a genius, particularly when it leads to such striking results" (ibid., 91). Similar remarks can be found about Owen Richardson's study of the electron, which Peter Galison describes as a 'simple' and 'elegant' series of experiments $(1980,32)$. Even in the case of thought experiments, simplicity and aptness seem to be at the forefront of appreciation. Brown, for instance, argues that Galileo's thought experiment on falling bodies is "the most beautiful thought experiment" due to its simplicity and originality (2004, 24). And while one might worry about the status of thought experiments, whether they are genuine experiments or not $^{3}$ (and we should certainly note that the materials employed between thought experiments and physical experiments are different),

\footnotetext{
3 There is an important discussion concerning what constitutes an experiment, where the debate tries to establish whether simulations, thought experiments and models constitute experiments. Morgan (2005) argues for the superiority and epistemic privilege of physical experiments over models and simulations on two grounds: (1) materiality requirement states that we can learn more about a target system that is made of the same stuff as the experiment, and the latter allows to intervene into nature while a simulation does not; and (2) only experiments can produce surprising results, privileging them over models and simulations. In contrast, Norton and Suppe (2001) argue that models and simulations are just another form of experiments. Parker (2009) challenges the materiality requirement, arguing that simulations are genuine experiments and can give us knowledge of target systems on which physical experiments are not possible, such as climate and economic models. Parke (2014) further challenges the idea that experi-
} 
the emphasis on aesthetic praise in both domains seems to be on the economy of the design.

So far I have argued that while there are clearly many experiments that offer visually pleasing features, which can be due to observing a beautiful natural phenomenon or even the experimental instruments and tools, the ultimate beauty of experiments lies in their design and significance. Experiments are beautiful because of the simplicity, elegance, economy and aptness of their design, showing the creative and imaginative thinking of the experimenters. To illustrate this, I now explore in more depth the reception of one particular experiment, often referred to as 'the most beautiful experiment in biology', the famous experiment by Matthew Meselson and Franklin Stahl that determined how DNA replicates. ${ }^{4}$ Meselson and Stahl aimed to understand the process by which the DNA replicates, a question that became central after the discovery of the double-helical structure of DNA in 1953. Three different hypotheses were proposed: (1) conservative replication, proposed by Gunther Stent, according to which each of the two strands of the parent DNA molecule are replicated in the new; (2) semi-conservative replication, proposed by James Watson and Francis Crick, according to which one strand of the parent DNA is conserved in the daughter DNA; and (3) dispersive replication, proposed by Max Delbrück, suggesting that the parent DNA chains break at intervals, with the parental segments combining with new segments to form the daughter DNA.

In 1958 Meselson and Stahl published the results of an experiment they performed a year earlier that is broadly regarded to have conclusively supported the semi-conservative replication and discredited the alternative hypotheses. Meselson and Stahl fed bacteria nutrients containing heavy nitrogen isotope that through metabolising is incorporated into the bacterial genetic material. They continued the process until the genetic material of the bacteria became heavy. Then they fed the bacteria light nitrogen and studied the genetic material of the bacteria through the next generations. Using ultracentrifugation to separate light from heavy genetic material, they obtained ratios of light heavy and hybrid DNA compatible with the semi-conservative replication. They obtained a band of intermediate density in the first generation, while a combination of intermediate density and light density followed in the next generation. The results were seen to disconfirm the conservative and dispersive replication hypothesis, since

\footnotetext{
Footnote 3 (continued)

ments hold epistemic privilege over simulations, showing that materiality is often not the relevant aspect that can reveal knowledge about the target system. In addition, Brown (1986) suggests that like physical experiments, thought experiments allow us to discover new knowledge. And when it comes to the argument from surprise, Currie (2018) shows that simulations can produce productively surprising results and French and Murphy (forthcoming)) further show that thought experiments can also surprise us in productive ways. In this paper I adopt a pluralist approach to experiments.

4 Here I focus on how the experiment has been received and praised by scientists and historians, for a detailed analysis of the experiment itself and the inferences drawn from the obtained results, see Bateu (2019), Franklin and Laymon (2020), Holmes (2008) and Weber (2019).
} 
the former predicts only light and heavy DNA in the next generations, while the latter entails only intermediate density DNA (Holmes (2008), Ivanova (2021b)).

The scientific community has praised this experiment for its beauty, but what is it about it that is beautiful? If we look in the scientific community for answers, we find a range of responses when it comes to the aesthetic evaluation and reception of this experiment, which I classify into two categories: (1) the design of the experiment: elegant, simple, apt and original; and (2) simple, clear, conclusive, important results. Let us explore these aspects in more detail.

Starting with the significance of the design, one aspect that has been noted is the elegant and original idea behind how Meselson and Stahl set up the experiment. For instance, Ernst Peter Fischer argues that:

One condition of this experiment consisted in making the genetic material physically heavier without changing it chemically. There is something beautiful in this idea alone, the understanding that the chemical properties of an atom-for example, its ability to bond with other atoms-are determined by its external electrons, whereas the physical properties-for example, the mass-are hidden inside the atomic nucleus. (1999, 21)

This consideration regards the elegance and aptness of the experiment, the experimenters setting up the experiment in the most optimal way to obtain the results. Holmes also praises the simplicity of this experiment, arguing that the simple steps of the experiment and its results make it ideal for pedagogical purposes:

The beauty of the Meselson-Stahl experiment is invariably connected with its simplicity. When reduced to its essential features, it is readily understood even by beginning students of the life sciences. Teachers look on it with fondness for the ease with which its message can be conveyed (2001, ix).

Holmes notes that many scientists praise the simplicity of this experiment because it is easy to explain it to students, it is easily visualised, the steps are easy to grasp, and the results and significance of the experiment are easy to appreciate (ibid., 427). Holmes argues that the Meselson-Stahl experiment is seen as a model experiment and is regularly used when teaching introduction to molecular biology.

Another feature pertaining to the aptness and originality of this experiment is the use of centrifugation in extraction of the genetic material. This step in the experiment shows innovative design and was widely regarded as beautiful. Throughout the history of science we have praised the creative thinking behind the novel involvement of methods, techniques and instruments fitting for the purpose of the experimenter. Studies of the vacuum utilised the newly invented air pump, the interferometer was an invention aimed to enable measurement of the velocity of the earth relative to the ether; currently we use complex technologies and machine learning algorithms in modern experiments in physics, ecology, medicine both to obtain, process and find significant results. Similarly, with the use of centrifugation Messelson and Stahl resolved a difficulty about experimental 
studies on DNA at the time, they employed a highly suitable way of labelling the DNA strands, which was original and innovative. The important point to stress is that the involvement of innovation, creativity and imagination of the experimenter themselves is inherently related to the aptness of the design.

Another important feature of the Meselson-Stahl experiment is the significance of its results, we often find scientists arguing that the results were 'clean' and 'solid', the experiment is seen to be an exemplar of a crucial experiment, confirming one hypothesis while disconfirming its competitors (Franklin and Laymon (2020), Weber (2019)). Franklin and Laymon (2020) and Holmes (2008) argue that the results are so clear and immediate, there was no need for replication, they spoke conclusively in defence of semi-conservative replication. Stahl himself notes that the results exhibit notable clarity in the sense that there is no need for their interpretation, they exhibit a sense of completeness and conclusiveness. ${ }^{5}$ Fischer further adds that "the Meselson-Stahl experiments speak for themselves and made all further commentary superfluous" (1999, 21).

If we go back to the central debates in the contemporary literature on aesthetics in science, outlined in Sect. 2, we can ask whether judgements about experimental design are stable across different time periods, or whether they are dynamic. From our discussions so far it is clear that experimental practice has certainly changed, so perhaps we can expect the aesthetic values associated with such practices to change too. The table-top experiments performed by natural philosophers were rather simple and their results immediately perceived by the senses, they involved relatively cheap equipment and were performed by one scientist. In contrast, today large-scale experiments are designed and run by international communities and involve highly complex machinery. Does this mean experiments at different experimental periods are appreciated differently? I think some aspects of aesthetic appreciation of experiments have certainly changed and this reflects the diversity of experimental set ups. For instance, experiments today hardly involve immediately perceiving the results and they certainly lack the performative dimension on seventeenth century experiments. However, I also think there is scope to consider aptness and economy in design as relevant aspects of appreciation in today's experiments just as in those experiments in different experimental periods, even if there are differences in how these design aspects are manifested. Despite the complexity of modern experiments, the materials and steps involved in their design, central aspect of appreciation remains how well the experiment is designed for purpose and whether it is optimal. This preference for economy and aptness can be seen as a product of cognitive and material limitations, ultimately shaping our aesthetic appreciation for the design that most economically achieves a purpose (Ivanova (2020)).

So far we have explored aspects of the experiments pertaining to design. But as noted earlier, beautiful experiments do not only exhibit pleasing design, they also do

\footnotetext{
5 Tudor Baetu (2020) however challenges the idea that the results spoke so clearly in favour of the semiconservative replication arguing that some of the auxiliary assumptions made by the experimenters needed to receive further support, making the conservative hypothesis still a viable option at the time Meselson and Stahl published and result, condemning it only after further experiments were carried out.
} 
something significant: they discover, confirm. What does this imply for the question at hand: is an experiment beautiful only when it is successful? Answering this question is the focus of the next section.

\section{From Design to Significance: On the Diversity of Experimental Aims}

In the last section we saw that one aspects for which the Meselson-Stahl experiment has received the status of 'the most beautiful experiment in biology' regards the significance of its results. The experiment is often regarded as an example of a crucial experiment, even by those who acknowledge the Duhemian worries behind the concept. ${ }^{6}$ The significance of the results, their ability to speak decisively in favour of one hypothesis over alternatives, is a significant aspect of aesthetic praise for this experiment. Similar focus on the significance of the results has been noted by Crease (2002), who discusses a number of beautiful experiments in science that do not only exemplify good design but also achieve significant results: they extend our knowledge by discovering new particles or confirming a scientific theory. In this section I focus on the questions: (1) how do we understand the significance of a scientific experiment?; and (2) is focusing on discovery or confirmation doing justice to the plurality of experimental aims in conducting an experiment? I then proceed to defend a pluralistic approach to experiments and argue that experiments can elicit a number of different aesthetic responses.

Let us start with the idea about the immediateness of the obtained results. Holmes argues that the Meselson-Stahl experiment obtains the results in an immediate sense, claiming that the experiment was constituted by a 'singular historical event', observed by the individual scientist, it was not repeated afterwards (2008, 431). This is an important observation, but Holmes himself recognises that many experiments in science will not exhibit such simplicity and immediateness of the obtained results. ${ }^{7}$ We certainly do not expect results to have such immediateness in experiments in high-energy physics, for instance, where the experiment stretches over the borders of countries, involves thousands of scientists, and the analysis of the obtained data is a timely and laborious process. Experiments in the Large Hadron Collider at Cern, for instance, lack 'immediateness', because analysing the outcome

\footnotetext{
${ }^{6}$ Pierre Duhem (1906) challenges the idea that experiments can conclusively speak in favor of a theory we test or decisively condemn it, due to the holistic nature of theory testing. Since out hypotheses are always tested together with a number of other theories and assumptions employed in the set up of the experiment, an anomalous result could indicate fault in the hypothesis we test or in the other assumptions. The logical structure of the reasoning here does not allow us to discriminate where the fault lies. Solutions to Duhem's problem have been discussed by Dietrich and Honenberger (2020) and Ivanova (2021a). When it comes to the Meselson-Stahl experiment, Weber (2019) argues that despite the seriousness of Duhem's problem, this is a case of a crucial experiment in science.

7 As mentioned earlier, Baetu (2020) objects to the idea that the experiment produced such solid results, arguing rather that for the results to be solidified, further experiments were needed to confirm an auxiliary assumption on which the original experiments relied on. Thus, he sees the original results as 'fragile' rather than undisputable.
} 
of a measurement is a complex process of statistical analysis and deciding whether the experimental data constitutes an 'event' takes time to settle (Beauchemin (2017)). If we take, for instance, one of the most recent discoveries in particle physics, the discovery of the Higgs boson, we can appreciate that there was hardly anything immediate about the discovery. There was a timespan of deliberations before the community decided a new particle had been detected, as Mättig and Stöltzner (2019) have nicely documented, with the community carefully announcing that 'a Higgs-like particle' had been detected. All this is to say that many experiments will not exhibit such clear, immediate results as in the case of the Meselson-Stahl experiments, and there will be lengthy deliberations to establish the significance of the results. Furthermore, contrary to earlier experiments where we get to perceive a phenomenon unfolding and could often appreciate the significance of the result as the experiment takes place, in contemporary large scale experiments we lack both immediateness and a sense in which we get to 'perceive' the results and their aesthetic qualities. While it is important to note that not all experiments have directly and immediately perceivable results, this difference is hardly surprising. After all, even in art the appreciation of beauty and aesthetic value more broadly is not always due to perceptual features, and while the aesthetic response can be immediate in some cases, it is certainly not necessary in the case of many artworks. Just like we need some time and work to appreciate the aesthetic value of a novel or a multi sensory art installation, we need time to appreciate the aesthetic value of a theorem, a theory or an experiment and its outcomes.

We also need to acknowledge some of the problems surrounding the nature of discoveries. We can appreciate the appeal of the claim that a beautiful experiment is the one that leads to a discovery, given how much novelty is valued in science. As the sociologist Robert Merton famously observed, science is driven by the priority rule (Strevens (2013); we reward and praise those who discover first, leading to, among other things, the replication crisis (Hessen (2018)). It is no surprise, then, that even if two experiments exhibit the same properties, for instance they share an elegant design, we might still be inclined to value the one that led to the discovery, just like we value original painting and not their forgeries or copies. Our attribution of value to priority pertains to our valuing originality and creativity, which leads us to think about the nature of creativity and the imagination in science. ${ }^{8}$ But many have challenged our practices of credit attribution by pointing out to the plurality and contingency of discoveries. For instance, in his illuminating study of the discovery of positions Peter Galison (1982) asks 'when was the positron discovered?' and argues that we can credit three different schools that were directly responsible for the work on the positron. Simon Schaffer (1996) has also extensively highlighted the contingency and plurality behind discoveries in science, challenging our idea that our practices of credit attribution are justified towards those who discover first. Shaffer highlights the sociological and often political factors in choosing a discoverer, given

\footnotetext{
8 There is an exciting recent literature on creativity and the imagination in science, see Anscomb (2021), Breitenbach (2020), French (2020a, 2020b), Hills and Bird (2018), Langland-Hassan (2020), Murphy (2021), Salis and Frigg (2020), Sánchez-Dorado (2020), Shevlin (2021), and Stuart (2019).
} 
the fact that often discoveries are made hand in hand by many scientists and groups in parallel, and he insightfully argues that the story of the discoverer has significance for the formation of institutional identity. These studies call us to reconsider the significance of discoveries and who is the discoverer. One interesting observation here is that while traditional studies of creativity have analysed it in terms of individual inspiration, computation, or epistemic virtue, in the context of big science and collaborative discoveries we are now asking whether creativity is a property or virtue of communities rather than individuals (Currie (2019), Ivanova and French (2020), Ritson (2021)). And an even more uncharted question about the nature of creativity and credit attribution emerges in the context of computer-assisted discoveries and the role of machine learning algorithms in modern scientific discoveries (Ivanova (forthcoming)).

So far we have identified two ways in which experiments have been regarded beautiful due to their significance: they discover a new particle or phenomenon, or they confirm a hypothesis and eliminate other contenders. But while these two achievements are certainly important, and the focus of aesthetic appreciation, I want to now focus on the plurality of experimental goals and argue that we need to account for the diversity of experimental aims in our framework. I think that focusing on discovery and confirmation for attribution of aesthetic value is limiting, because experiments are performed with a plurality of aims in mind that go beyond the search to confirm a hypothesis or discover the existence of a particle or phenomenon. Some of these other aims include the exploration of new domains and uncovering phenomena that need not be accommodated within an existing theoretical framework. For instance, one of the aims of the LHC experiments certainly is to offer support to the standard model by finding a particle the theory had predicted. The detection of the Higgs boson in 2014 offered significant support to the standard model that had predicted the existence of the particle. But the aims of this experiment go way beyond a simple 'tick' against the name of the standard model. With these experiments, particle physicists aim to explore and study a range of energy never before accessible to physics, the deep TeV energy range, and these explorations in their turn are hoped to give insight into how we can develop physics beyond the standard model. This is the lesson we learn from Galison (1980), Cartwright (1983), Hacking (1983), Franklin (1986) and Mayo (1996): experiments have diversity of aims, they are not there just to check the correctness of a theory, or just to discover theoretically predicted particles and phenomena, they can explore systems without theoretical framework, and can have their own tools of judging the significance of the result, whether it is a genuine one of an artefact. This work sheds light onto the many reasons why experiments are carried out, the experimentalist traditions in which experiments are designed and carried out, and the ways in which their results are evaluated, with Galison (1980) arguing that different schools can reach different conclusions with regard to what an experimental result entails..

With this in mind I want to bring our attention to experimental results that are neither confirming nor discover in a straight-forward sense, rather, they are surprising and even disruptive. What can we say about their aesthetic value? Do such experiments have aesthetic value or do the disruptive results diminish the aesthetic appeal of an experiment? Take for instance the famous Michelson and Morley experiment 
designed to measure the velocity of the earth relative to the ether. Besides the elegant design of the experiment itself, Michelson himself created a highly sophisticated apparatus, the interferometer, specifically designed to achieve the goal of the experiment, by crafting one of the most precise instruments in the history of science capable of detecting very small effects. In the words of historian of science Gerard Holton "nobody before Michelson was able to imagine and construct an apparatus to measure the second-order effect of the presumed ether drift. The interferometer was a lovely thing" $(1969,135)$. When we think about the aesthetic dimension of this experiment, it was clearly a well-designed experiment embodying the imagination and creativity of the experimenters. Albert Einstein himself remarked that the design of the experiment made Michelson "the Artist in Science", who derived joy from "the beauty of the experiment itself, and the elegance of the method employed" (Holton 1969, 157). However, contrary to the Messelson-Stahl experiment in molecular biology or the LHC detection of the Higgs boson, the MichelsonMorley obtained a null result. The failure to detect ether drift was a disruptive result that led to significant conceptual changes in physics. How can we understand the aesthetic significance of experiments that in a sense do not deliver on what they were designed to do?

I think there is scope to take some such surprising and disruptive results to be part of a broader aesthetic experience that experiments can elicit. By recognising the plurality of aesthetic experiences, ranging from beauty experiences to experiences of awe, amusement and even sublime experiences, we can start to make sense of how disruptive experiments can elicit aesthetic responses. Unexpected and disruptive results provoke our wonder because they come in friction with our theoretical frameworks and ask us to reconsider out most fundamental assumptions. Sophie Ritson (2020) has reflected on the recent disruptive results at the LHC that caused the community even more excitement than the Higgs discovery, and she argues that the value of these results is exactly in their disruptive nature. While the results turned out to be fluctuations in the detector, during this time the community was forced to deliberate the nature of our most fundamental assumptions in particle physics. Such probing results do not confirm a theory or speak in favour of the existence of an entity, rather they are anomalous and invite further investigation, and it is in such further investigation and engagement that importance has been placed on the very nature of surprise in experimental results.

The earlier discussion on the aims of the experiments ran by at the Large Hadron Collider at Cern is instructive to illustrate this argument. Recall that one of the goals of these experiments is to detect particles predicted by the standard model, this includes the Higgs boson as well as super symmetric particles (susy). Similarly to the case of the ether experiments, susy particles have not been detected at the LHC. How should we understand these results and their aesthetic dimension? I think we can accommodate the aesthetic significance of such disruptive results by adopting a broader perspective on the nature of aesthetic experiences. We can see the failure to detect susy as a disruptive result, as an invitation to reconsider not only our current physical theory, the standard model, but perhaps even more significantly, to question the very constitutive principles that have guided the development of physical theories in the last century—-symmetry principles, naturalness and 
simplicity. These results are surprising, disruptive and valuable exactly because they do not fit our existing theoretical framework and thus provoke further exploration and engagement.

It is with this appeal to disruptive and null results that I would like to bring us back to the discussion of aesthetic value of experiments. Beautiful experiments can do many things - they can confirm our theories, they can discover new particles, but they can also guide us to identify the limitations of our knowledge and probe us to further investigations. And the latter very much reflect the experience of awe, wonder, mystery and disruption that scientists often refer to when they uncover an unexpected or unaccounted for event. I think we can accommodate the diversity of roles experiments can play by adopting a broader notion of the aesthetic response. Just like artworks can be disruptive and break away with past artistic practices and traditions to invite us to reconsider our assumptions about the nature of art, artistic expression, the concept of beauty and the aesthetic experience, experiments can elicit a diversity of aesthetic responses too. Experiments can be beautiful, pleasing and positive and we can appreciate the aesthetic nature of the experimental results both when nature behaves as we expect but also when it does not, generating a sense of awe, surprise, mystery and wonder, even sublime experiences. ${ }^{9}$ Such aesthetic responses can be seen to play a cognitive role in science, since they invite us to identify the limitations of our knowledge and further deepen our engagement with the subject. We can thus account for the productive and cognitive significance of such disruptive or surprising results in scientific experiments and the aesthetic response they give rise to by recognizing the spectrum of the aesthetic responses and the diversity of aims experiments are designed to fulfill. As a consequence, I have argued that our aesthetic appreciation of experiments is due both to their design and their significance, and the latter can be understood more broadly to include not only experiments that confirm or discover but that prompt productive investigations that are transformative of our knowledge.

\section{Conclusion}

This article explored a rather neglected question in current philosophy of science: what constitutes a beautiful experiment? I identified two ways in which we could make a judgement with regard to the aesthetic value of an experiment. One is to identify the aesthetic value of the experiment by focusing on its design: its simplicity, economy, elegance and aptness. We identified a commonality between aesthetic praise of experiments and that of scientific theories, since the latter are also appreciated with the same set of values in mind, even if those are measured differently.

\footnotetext{
9 Arcangeli and Dokic (2020) have drawn an interesting analogy between the experiences of beauty and sublime with how we, as cognitive agents, process information. They take beauty experiences to be associated with fluency processing, when information is easy to process by fitting into previously explored patters, while the sublime experience is more disfluent, drawing the attention of the scientist to challenging phenomena and domains of enquiry that require attention for the advancement of our understanding.
} 
However, I also argued that we do not only praise the design of an experiment but its significance, what the experiment helps us achieve. I defended a more pluralistic role for scientific experiments and argued that we can understand the aesthetic value of experiments that fulfil very different roles and make different contributions. Experiments that offer us results we expect from the start-for instance by detecting a particle our theory has predicted, or by offering empirical support for a hypothesis-do not necessarily surprise us in a probing way; they often align with our expectation (and that is no bad thing!). We find them beautiful for the same reasons we find simple and elegant theories beautiful, they are easier for us to work with and understand. But some experiments, that have unexpected and disruptive results, can trigger a different aesthetic response, more in line with our sense of smallness, awe and wonder. They can make us identify limitations in our understanding and probe us to reconsider or further develop our knowledge. Both are aesthetic experiences that feature in the reception of an experiment and both play a cognitive role in science.

Acknowledgements I am grateful to Steven French and Alice Murphy for reading an earlier version of this paper and offering me such enthusiastic comments as well as Hasok Chang and his group of graduate students who discussed the paper with me in their seminar. Many thanks are also due to the two referees for this journal for their encouraging and helpful feedback. I have had the privilege to discuss this work with audiences in Aarhus, Bristol, Cambridge, Geneva, Haifa, Hertfordshire, Kent, Oxford, Turin, and Uppsala, and would like to thank them all for the great discussions.

Open Access This article is licensed under a Creative Commons Attribution 4.0 International License, which permits use, sharing, adaptation, distribution and reproduction in any medium or format, as long as you give appropriate credit to the original author(s) and the source, provide a link to the Creative Commons licence, and indicate if changes were made. The images or other third party material in this article are included in the article's Creative Commons licence, unless indicated otherwise in a credit line to the material. If material is not included in the article's Creative Commons licence and your intended use is not permitted by statutory regulation or exceeds the permitted use, you will need to obtain permission directly from the copyright holder. To view a copy of this licence, visit http://creativecommons.org/licen ses/by/4.0/.

\section{References}

Anscomb, C. (2021). Visibility, creativity, and collective working practices in art and science. European Journal for Philosophy of Science, 11, 5. https://doi.org/10.1007/s13194-020-00310-z

Beauchemin, P. H. (2017). Autopsy of measurements with the ATLAS detector at the LHC. Synthese, $194,275-312$.

Baetu, T. (2019). On the possibility of crucial experiments in biology. The British Journal for the Philosophy of Science, 70, 407-429.

Beardsley, M. C. (1982). Aesthetic experience. In D. M. Callen, M. J. Wreen, \& M. C. Beardsley (Eds.), The aesthetic point of view: Selected essays (pp. 285-297). Cornell University Press.

Breitenbach, A. (2020) One Imagination in Experiences of Beauty and Achievements of Understanding, The British Journal of Aesthetics, pp. 71-88

Breitenbach, A. (2013). Aesthetics in science: A Kantian proposal. Proceedings of the Aristotelian Society, CXIII, 83-100.

Brown, J. R. (2004). Why thought experiments transcend experience. In C. Hitchcock (Ed.), Contemporary debates in philosophy of science(pp. 23-43). Blackwell.

Brown, J. R. (1986). Thought experiments since the scientific revolution. International Studies in the Philosophy of Science, 1(1), 1-15. 
Bueno, O. et al. (2017). Thinking about science, reflecting on art: Bringing aesthetics and philosophy of science together. Routledge.

Carlson, A. (1993). Appreciating art and appreciating nature. In S. Kemal \& I. Gaskell (Eds.), Landscape, natural beauty and the arts. Cambridge: Cambridge University Press.

Carlson, A. (2011). Aesthetic appreciation of nature and environmentalism. Royal Institute of Philosophy Supplement, 69, 137-155. https://doi.org/10.1017/S1358246111000257

Carroll, N. (2002). Aesthetic experience revisited. The British Journal of Aesthetics, 42(2), 145-168.

Cartwright, N. (1983). How the Laws of physics lie. Oxford University Press.

Cellucci, C. (2015). Mathematical beauty, understanding, and discovery. Foundations of Science, 20, $339-355$.

Chandrasekhar, S. (1987). Truth and beauty: Aesthetics and motivation in science. The University of Chicago Press.

Clarke, B., \& Ambrosio, C. (2018). The nervous system and the anatomy of expression: Sir Charles Bell's anatomical watercolours. In C. Ambrosio \& W. MacLehose (Eds.), Imagining the brain: Episodes in the history of brain research (pp. 109-138). Elsevier.

Crease, R. (2002). The most beautiful experiment, Physics World, May 2

Currie, A. (2020). Epistemic engagement, aesthetic value \& scientific practice. British Journal for Philosophy of Science. https://doi.org/10.1086/714802

Currie, A. (2019). Creativity, conservativeness and the social epistemology of science. Studies in the History and Philosophy of Science, 76, 1-4.

Currie, A. (2018). The argument from surprise. Canadian Journal of Philosophy, 48(5), 639-661.

Dietrich, M., \& Honenberger, P. (2020). Duhem's problem reviited: Logical vs epistemic formulations and solutions. Synthese, 197, 337-354.

Duhem, P. (1954 [1906]). The aim and structure of physical theory. Princeton University Press.

Elgin, C. Z. (2020). Epistemic gatekeepers. In M. Ivanova \& S. French (Eds.), The aesthetics of science: Beauty, imagination, understanding (pp. 21-36). London: Routledge.

Elgin, C. Z. (2018). True enough. The MIT Press.

Elgin, C. Z. (2014). Fiction as thought experiment. Perspectives on Science, 22, 221-241.

Fischer, E. P. (1991). Beauty and the beast: The aesthetic moment in science. Springer.

Franklin, A. (1986). The neglect of experiment. Cambridge University Press.

Franklin, A., \& Laymon, R. (2020). Once can be enough: Decisive experiments, no replication required. Springer.

French, S., \& Murphy, A. (2021). The value of surprise in science. Erkenntnis. https://doi.org/10.1007/ s10670-021-00410-z

French, S. (2020). Imagination in scientific practice. European Journal for Philosophy of Science. https:// doi.org/10.1007/s13194-020-00291-z

French, S. (2020). Performance and practice: Situating the aesthetic qualities of theories. In Milena Ivanova \& Steven French (Eds.), The aesthetics of science: Beauty, imagination, understanding (pp. 186-211). Routledge.

Frigg, R., \& Hunter, M. eds. (2010). Beyond mimesis and convention - representation in art and science. Springer.

Frigg, R., \& Hunter, M. (2008). Beyond mimesis and convention: Representation in art and science. Boston Studies in Philosophy of Science

Galison, P. (1987). How experiment end. Chicago University Press.

Godrey-Smith, P., \& Levy, A. eds. (2020). The scientific imagination. Oxford University Press.

Hacking, I. (1983). Representing and intervening: Introductory topics in the philosophy of natural science. Cambridge University Press.

Hessen, R. (2018). Why the reward structure of science makes reproducibility problems inevitable. The Journal of Philosophy, 115, 661-674.

Hills, A., \& Bird, A. (2019). Against creativity. Philosophy and Phenomenological Research, 99, 694-713.

Holmes, F. L. (2008). Meselson, stahl, and the replication of DNA (pp. 83-101). Yale University Press.

Holmes, F. (1996). Beautiful experiments in the life sciences. In A. I. Tauber (Ed.), The elusive synthesis: Aesthetics and science. Kluwer.

Hossenfelder, S. (2018). Lost in math: How beauty lead physicists astray. Basic Books.

Ivanova, M., \& French, S. (2020). The aesthetics of science: Beauty, imagination, understanding. London: Routledge. 
Ivanova, M. (forthcoming). Scientific progress and aesthetic values. In Y. Shan (Ed.), New philosophical perspectives on scientific progress. Routledge.

Ivanova, M. (2021a). Duham and holism. Cambridge University Press.

Ivanova, M. (2021b). The aesthetic of experiments. Philosophy Compass. https://doi.org/10.1111/phc3. 12730

Ivanova, M. (2020). Beauty, truth and understanding. The aesthetics of science: Beauty (pp. 86-104). Routledge.

Ivanova, M. (2017a). Aesthetic values in science. Philosophy Compass. https://doi.org/10.1111/phc3. 12433

Ivanova, M. (2017b). Poincaré's aesthetics of science. Synthese, 194, 2581-2594.

Kivy, P. (1991). Science and aesthetic appreciation. Midwest Studies in Philosophy, 26, 180-195.

Kuhn, T. (1977). Objectivity, Value Judgment, and Theory Choice. In The Essential Tension (pp. 320353). The University of Chicago Press.

Langland-Hassan, P. (2020). Explaining Imagination. Oxford University Press.

Mayo, D. G. (1996). Error and the growth of experimental knowledge. University of Chicago Press.

Mättig, P., \& Stöltzner, M. (2019). Model choice and crucial tests. On the Empirical Epistemology of the Higgs Discovery, Studies in History and Philosophy of Modern Physics, 65, 73-96.

McAllister. (1996). Beauty and revolution in science. Cornell University Press.

Meselson, M., \& Stahl, F. W. (1958). The replication of DNA in Escherichia coli. Proceedings of the National Academy of Science of the United States of America, 44, 671-682.

Montano, U. (2014). Explaining beauty in mathematics: An aesthetic theory of mathematics. Synthese Library (Vol. 370). Springer

Morgan, M. (2005). Experiments versus models: New phenomena, inference and surprise. Journal of Economic Methodology, 12(2), 317-329.

Murphy, A. (2021). Towards a Pluralist Account of the Imagination in Science. Philosophy of Science. https://doi.org/10.1086/710620

Murphy, A. (2020). The aesthetic and literary qualities of scientific thought experiments. In M. Ivanova \& S. French (Eds.), The aesthetics of science: Beauty, imagination, understanding. (pp. 146-167). London: Routledge.

Norton, J. D. (1991). Thought experiments in Einstein's work. In T. Horowitz \& G. J. Massey (Eds.), Thought experiments in science and philosophy. (pp. 129-144). Rowman \& Littlefield.

Norton, S., \& Suppe, F. (2001). Why atmospheric modeling is good science. In C. Miller \& P. N. Edwards (Eds.), Changing the atmosphere: Expert knowledge and environmental governance (pp. 67-105). MIT Press.

Parker, W. S. (2009). Does matter really matter? Computer simulations, experiments, and materiality. Synthese, 169, 483-496.

Parke, E. (2014). Experiments, simulations, and epistemic privilege. Philosophy of Science., 81(4), $516-536$.

Parsons, G. (2012). The aesthetics of chemical biology. Current Opinion in Chemical Biology, 16, $576-580$.

Parsons, G. (2002). Nature appreciation, science, and positive aesthetics. The British Journal of Aesthetics, 42(3), 279-295. https://doi.org/10.1093/bjaesthetics/42.3.279

Parsons, G., \& Reuger, A. (2000). The epistemic significance of appreciating experiments aesthetically. British Journal of Aesthetics, 40, 407-423.

Potochnik, A. (2017). Idealization and the aims of science. University of Chicago Press.

Priestley, J. (1779). Experiments and observations relating to various branches of natural philosophy: With a Continuation of the Observations on Air (Vol. 2). Pearson and Rollason

Reuger, A. (1997). Experiments, nature and aesthetic experience in the eighteenth century. British Journal of Aesthetics, 37, 305-322.

Ritson, S. (2021). Creativity and modelling the measurement process of the Higgs self-coupling at the LHC and HL-LHC. Synthese. https://doi.org/10.1007/s11229-021-03317-y

Ritson, S. (2020). Probing novelty at the LHC: Heuristic appraisal of disruptive experimentation. Studies in History and Philosophy of Science Part B: Studies in History and Philosophy of Modern Physics, $69,1-11$.

Salis, F., \& Frigg, R. (2020). Capturing the scientific imagination. European Journal for Philosophy of Science. https://doi.org/10.1093/oso/9780190212308.003.0002

Sánchez-Dorado, J. (2020). Novel \& worthy: Creativity as a thick epistemic concept. European Journal for Philosophy of Science, 10, 40. https://doi.org/10.1007/s13194-020-00303-y 
Schaffer, S. (1996). Making up discovery. In M. Boden (Ed.), Dimensions of creativity (pp. 13-51). MIT Press.

Shevlin, H. (2021). Rethinking creative intelligence: Comparative psychology and the concept of creativity. European Journal for Philosophy of Science. https://doi.org/10.1007/s13194-020-00323-8

Strevens, M. (2003). The role of the priority rule in science. The Journal of Philosophy, 100(2), 55-79.

Stuart, M. T. (2019). Everyday Scientific Imagination. Science \&amp; Education, 28, 711-730. https:// doi.org/10.1007/s11191-019-00067-9

Todd, C. S. (2008). Unmasking the truth beneath the beauty. Why the supposed aesthetic judgments made in science may not be aesthetic at all. International Studies in the Philosophy of Science, 22, 61-79.

Turner, D. (2019). Paleoaesthetics and the practice of paleontology. Cambridge University Press.

Weber, M. (2019). The crux of crucial experiments: Duhem's problems and inference to the best explanation. British Journal for Philosophy of Science, 60(1), 19-49.

Wylie, C. (2015). 'The artist's piece is already in the stone': Constructing creativity in paleontology laboratories. Social Studies of Science, 45(1), 31-55.

Wragge-Morley, A. (2020). Aesthetic Science: Representing Nature in the Royal Society of London, 1650-1720. Chicago University Press.

Publisher's Note Springer Nature remains neutral with regard to jurisdictional claims in published maps and institutional affiliations. 